\title{
NO SÓLO NEGROS, SINO "ETÍOPES": LA APARIENCIA OSCURA DE LOS DEMONIOS EN LA VIDA DE SIMEÓN EL LOCO, DE LEONCIO DE NEÁPOLIS ${ }^{1}$
}

\author{
Francisco Javier FUERTES \\ BECARIO FPU, Universitad de Cantabria
}

\begin{abstract}
RESUMEN: Este trabajo pretende estudiar las epifanías demoníacas contenidas en la Vida de Simeón el Loco, concentrándose especialmente en una característica común a todas ellas: la apariencia oscura, descrita en ocasiones como "etíope", de los demonios en la obra. Tras situar las referencias demonológicas en el contexto narrativo del texto, el autor analiza, desde una perspectiva diacrónica y mediante el examen de paralelos textuales, las distintas tradiciones culturales y hagiográficas que explican y permiten comprender esta apariencia.
\end{abstract}

PALABRAS CLAVE: Etíopes, negros, demonios, hagiografía, santos locos.

ABSTRACT: This paper aims to study the demonical epiphanies within the Life of Symeon the Fool, focusing specially on a feature common to all of them: the dark appearance of demons in the work, described sometimes as "Ethiopian". After placing demoniacal references into the narrative context of the text, the author analyzes, from a diachronic perspective and by means of the study of textual parallels, the different cultural and hagiographical traditions which explain and make it possible to understand this appearance.

KEYWORDS: Ethiopians, blacks, demons, hagiography, Holy fools.

\section{SIMÉON DE EMESA, EL SANTO LOCO $\left(\Sigma A \Lambda^{\prime} O \Sigma\right)$ POR EXCELENCIA*}

Según L. Rydén, un santo loco (holy fool) « is a person who serves God under the guise of foolishness. In principle, the disguise is not discovered until the fool is dead. Then he or she becomes a saint. If the holy fool happens to be recognized earlier he runs away, or else commits an act that is so foolish that the rent in his disguise is repaired $»^{2}$. El término técnico utilizado para describir a este tipo de

${ }^{1}$ Recibido el 1 de julio de 2011. Aceptado en el consejo de 8 de noviembre de 2011.

* Este trabajo ha sido realizado dentro del marco del Proyecto HAR2010-15957 del Ministerio de Educación español y del Programa de Becas FPU de esta misma institución. 


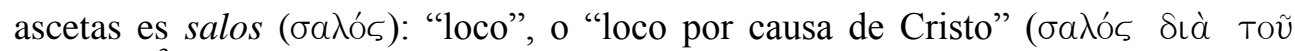
Xрıбтой) ${ }^{3}$. Se trata, en esencia, de un asceta que finge estar loco como una

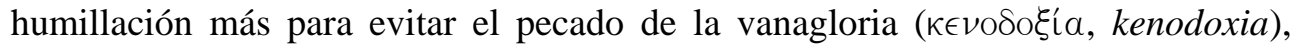
provocado por la admiración que suscita en los demás su ascesis, convirtiendo el deshonor en un ejercicio de virtud ${ }^{4}$. Esta práctica se justifica en las palabras de S. Pablo: "si alguno entre vosotros cree ser sabio en este mundo, que se haga necio

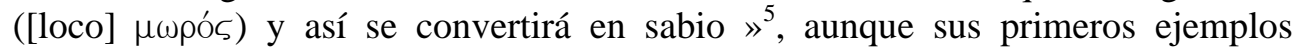
provienen de la Antigüedad Tardía, del siglo IV d. C. en adelante.

Según J. Grosdidier de Matons, pueden distinguirse dos grandes tradiciones en la Antigüedad Tardía y el Primer Bizancio (ss. IV-VII), que se corresponden básicamente con Egipto y Siria. Los saloí egipcios aparecen como ascetas pasivos, sufridores y humildes que actúan como locos buscando que otros les mortifiquen. Los sirios, por el contrario, son saloí más activos, que utilizan la locura para provocar a sus contemporáneos, censurar sus pecados y así corregir su comportamiento. Éstos últimos, además, tienen como rasgo particular poseer una impasibilidad sobrenatural (apátheia, amá $\theta \in \iota \alpha$ ) que los eleva por encima de la naturaleza humana, como bien ha señalado V. Deroché ${ }^{6}$.

${ }^{2}$ L. RYDEN (1981). «The Holy Fool». En HACKEL, S. (ed.). The Byzantine Saint. University of Birmingham Fourteenth Spring Symposium of Byzantine Studies, London, p. 106.

${ }^{3}$ El origen del término salos o salós (бa入ós) permanece desconocido. En el uso corriente del periodo era casi lo mismo que $\left.\mathfrak{\epsilon}^{\xi} \eta\right\rceil \chi O \varsigma$ (estúpido, simple de mente) y $\mu \omega \rho$ ós: loco (cf. J. Simón PAlMER, J. (1999). «Los santos locos en la literatura bizantina». Erytheia 20, pp. 57-58). Ha sido

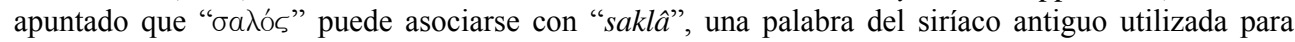
traducir el griego $\mu \omega$ ó́s (cf. L. RYDÉN (1981). op. cit., p. 107), pero no hay acuerdo. D. Krueger,

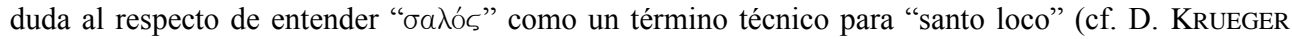
(1996). Simeón the Holy Fool. Leontius's Life and the Late Antique City, Berkeley/ Los Angeles/ London: University of California Press, pp. 62-66). La expresión "loco por causa de Cristo" aparece por vez primera en la Vida de Simeón el loco (J. SimÓN PALMER (1999), «Los santos locos...» p. 57). Para un estudio actualizado sobre los "santos locos", v. S. A. IVANOv (2006). Holy Fools in Byzantium and Beyond, New York: Oxford University Press.

${ }^{4}$ Cf. G. DAGRON, G. (1990). «L'homme sans honneur ou le saint scandaleux». Annales ESC, 4 (juillet-août), p. 932.

5 I Cor 3: 18. Realmente, en el Nuevo Testamento Pablo usa el término "moros" ( $\mu \omega \rho \operatorname{só})$, no salos; sin embargo, como apunta L. Rydén, sus palabras no pretendían incitar a los corintios a un comportamiento extravagante, sino dejar claro que el mensaje cristiano « is a matter of belief, not of reason and speculation »(L. RYDÉN (1981). op. cit., pp. 106-107).

${ }^{6}$ Para la distinción entre saloí egipcios pasivos y sirios pasivos cf. J. GROSDIDIER DE MATONS (1970). «Les thèmes d'edifications dans la Vie d'André Salos». Travaux et Mémoires 4, p. 296, y para la idea de apátheia: impasibilidad, como rasgo sobrenatural característico de los saloí sirios cf. V. Deroché (1995). Études sur Léontios de Néapolis, Uppsala: Uppsala Universitet, pp. 178, 180181. 
El más célebre de los santos locos bizantinos fue Simeón de Emesa (actual Homs, en Siria). Las primeras noticias sobre él las proporciona Evagrio Escolástico que, en su Historia Eclesiástica (IV, 34) de finales del siglo VI, lo sitúa bajo el

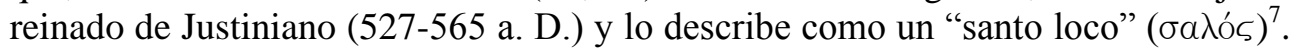
Pero la fuente principal sobre Simeón es la Vida de Simeón el loco, biografía escrita por el obispo Leoncio de Neápolis (actual Limasol, Chipre) en el siglo VII ${ }^{8}$. La obra describe la vida y los hechos de Simeón desde su juventud hasta su muerte. El relato se estructura en dos partes, de extensión similar pero de carácter completamente diferente (encuadradas ambas en un prólogo [121.1-123.27] y un epílogo [169.1-170.11], secciones breves, de estilo retórico, que dotan de marco a la historia $)^{9}$. Esta particular estructura condiciona también el retrato del personaje que proporciona el texto en cada parte.

La primera parte [124.1-145.18], describe la amistad entre Simeón y Juan, dos jóvenes de noble familia a la que ambos renuncian para hacerse monjes. También se cuenta su etapa cenobítica en el monasterio del abad Nikón y los años que pasaron después en el desierto, luchando contra el demonio de la lujuria. Finaliza con el regreso de Simeón al mundo para salvar almas. Esta parte está escrita en un

${ }^{7}$ Evagrio cuenta tres anécdotas sobre Simeón; en la primera una criada acusa al monje de haberla violado, pero no puede dar a luz hasta confesar la verdad; en la segunda Simeón alimenta en secreto a una prostituta y en la tercera él fustiga unas columnas evitando que un terremoto las derribe (Evagrio Escolástico, HE IV, 34). Para este autor, el salos es un desarrollo del cenobita y el boskós ("herbívoro", monjes que abandonaban el mundo para vivir en las zonas salvajes en compañía de Dios, rechazando el contacto humano y alimentándose de plantas silvestres) y representa el más alto grado de la vida monástica (ibid. I: 21). Sobre los hábitos de los boskoí v. S. ACERBI; R. TEJA (2011). «En las raíces del eremitismo cristiano: La vida en el desierto concebida como conquista del cielo en la tierra». En García de CortázAR, J. A. y TEJA, R. (coords). El monacato espontáneo. Eremitas y eremitorios en el mundo medieval, Aguilar de Campoo: Fundación $\mathrm{St}^{\mathrm{a}} \mathrm{M}^{\mathrm{a}}$ la Real, pp. 22-25.

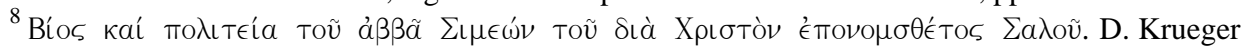
propone el periodo entre 642 y 649 d. C. para fechar la composición de la Vida de Simeón (D. KRUEGER (1996), op. cit., p. 5). La edición más prestigiosa es la de 1963 de L. Rydén (Das Leben des heiligen Narren Simeon von Leontius von Neapolis), editada en Uppsala, cuyo texto griego reproduce, con aparato crítico simplificado, traducción francesa e introducción, A. J. Festugière: A. J. Festugière (1974). Léontius de Neápolis, Vie de Simeón Le Fou et Vie de Jean de Chypre, Paris. He utilizado la edición de Féstugiere para el texto griego y también me he servido de la traducción española de J. Simón Palmer: J. Simón PALMeR (1999). Historias Bizantinas de locura y santidad. Juan Mosco, El Prado. Leoncio de Neápolis, Vida de Simeón el loco, Introducción traducción y notas de José Simón Palmer, Madrid: Siruela [en adelante VSym; los números entre corchetes indicarán la paginación del texto griego en la edición de Festugière, que en última instancia reproduce la de Rydén].

${ }^{9}$ Cf. A. Y. SYRKIN (1982): «On the Behaviour of the "Fool for Christ' Sake». History of Religions, 22 (Nov. 1982), p. 154, donde aparece la división estructural de la obra en cuatro secciones: prólogo, epílogo y las dos partes principales, que se ha hecho tradicional. 
estilo retórico, sintácticamente complejo, que incluye largos discursos. En ella, los acontecimientos suceden en orden cronológico, Simeón se comporta siempre de forma decorosa y la historia se sitúa mayoritariamente en el desierto.

La segunda parte de la obra [145. 19-168.28] está dedicada a la estancia de Simeón en Emesa. Comienza con su llegada a la ciudad y termina con su muerte. Son 31 episodios breves, escritos en un estilo coloquial, que forman una colección de anécdotas sin orden cronológico sobre milagros, hechos piadosos y ultrajantes bufonadas del monje. El comportamiento de Simeón se vuelve chocante y escandaloso, como los actos de un loco. Arroja piedras a las mujeres en la iglesia, [146], defeca en la plaza pública [148], camina desnudo por la ciudad, juega con prostitutas y bailarinas en la calle [154-155], devora pasteles en Jueves santo [156], se finge poseído por demonios [162], etc.

\section{LOS ELEMENTOS DEMONOLÓGICOS EN LA VIDA DE SIMEÓN EL LOCO (VSYM)}

Las diferencias formales y estilísticas entre las dos partes de la VSym también pueden percibirse en uno de los elementos típicos de la hagiografía antigua y bizantina: los episodios demoníacos, aquellos momentos en los que el monje tiene que hacer frente a las tentaciones o el acoso de sus malignos adversarios, los demonios, siempre decididos a impedir su progreso espiritual ${ }^{10}$. En la VSym lo cierto es que estos episodios no tienen un excesivo protagonismo, pero, aún así, tampoco dejan de estar presentes a lo largo del texto.

La mayor parte de las referencias demoníacas se concentran en la primera parte de la obra, mientras Simeón y su "hermano" Juan van progresando en su desarrollo espiritual en el desierto, tras abandonar el monasterio de Nikón. La lucha con los espíritus malignos consiste aquí en resistir sus tentaciones, enfocadas en tres aspectos: a) alimentar el recuerdo de sus familiares [137], b) excitar sus pasiones corporales, como el hambre o el deseo sexual [138], y c) hacerles aborrecer la práctica ascética [138, 139]; todo con el objetivo de que abandonen la vida monástica. Se trata, en suma, de un combate interno en el que los enemigos son

\footnotetext{
${ }^{10}$ Por razones de espacio y de ajuste temático, no se puede abordar aquí la compleja historia de la demonología cristiana de los primeros siglos, sobre ésta, simplemente a modo de referencia v. F. Viller; F. Cavallera; J. DE Guibert (1957). Diccionnaire de Spiritualité ascétique et mystique, III, Paris: Beauchesne, voz: démon (pp. 142-189); Monaci Castagno, A. (1996). Il Diavolo e $i$ suoi Angeli. Testi e tradizioni (secoli I-III), Fiesole: Nardini editore; S. PRICOCO (1995). Il Demonio e $i$ suoi Complici. Dottine e credenze demonologiche nella Tarda Antichità, Messina: Rubettino; E. SORENSEN, (2002). Possession and Exorcism in the New Testament and Early Christianity, Tübingen: Mohr Siebeck.
} 
Satán, como tentador universal [138] y los demonios de los vicios [135] ${ }^{11}$. Estas nociones están completamente en línea con las creencias monásticas de la Antigüedad Tardía, tradición textual de la que en última instancia proviene el texto de Leoncio.

Por el contrario, durante la segunda parte de la obra, aunque los episodios demoníacos son mucho más escasos (de hecho la mayoría de las alusiones a una presencia demoníaca se refieren al propio Simeón, considerado por su comportamiento como un poseso o un agente de Satanás), también son mucho más vistosos y espectaculares. Simeón se ha convertido ya en un monje espiritual libre de pasiones que se enfrenta ahora a unos demonios que centran su actividad sobre otras personas. Los demonios han dejado en esta segunda parte de la VSym de ser tentadores sutiles; ahora destrozan cosas, poseen hombres y animales y atormentan a sus víctimas "golpeándolas" para inducirles una especie de trance epiléptico. Sus acciones generalmente vienen precedidas por una falta moral, como el adulterio o la herejía, que pone a los pecadores a su merced.

En sentido estricto, sólo hay cuatro enfrentamientos entre el monje y los espíritus malignos en la segunda parte de la obra: un encuentro en las calles de Emesa, dos exorcismos y una disputa por un alma. De ellos, sólo en los tres últimos se describe la forma que adoptan los demonios: en el primero, un perro negro, en los otros dos, un etíope. En el presente estudio me centraré en investigar este aspecto etiópico de los demonios, aunque sin perder de vista el primero, que también servirá para mi argumentación. Analizaremos, en primer lugar, los pasajes relativos a este aspecto etiópico.

En el primero de ellos, Simeón libera a un muchacho de un demonio que lo ha poseído, de forma silenciosa, tras haber estado fornicando con una mujer casada. El joven era hijo del diácono Juan, amigo de Simeón. Percatándose el santo del estado del muchacho, se acercó a él mientras jugaba a correr con sus amigos y le golpeó diciéndole: "Deja de fornicar, miserable, y no se te acercará el demonio". En ese

\footnotetext{
${ }^{11}$ Durante su bautismo, Nikón realiza un exorcismo sobre Simeón y Juan para evitar que los

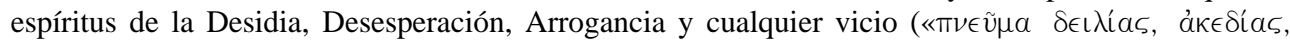

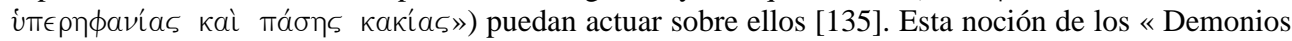
de los vicios » tiene un largo recorrido en el Cristianismo. Está presente en los Evangelios (cf. Mt 12: 45, $L c$ 11: 26), pero provendría en realidad del sincretismo judeo-helenístico, en el que las que una vez fueron las siete divinidades astrales babilónicas acabaron siendo consideradas poderes malignos que gobernaban los distintos cielos. Son los archontes gnósticos, llamados cosmocrátores por Pablo en Ef 6: 12 (cf. E. R. DodDS (1975). Paganos y cristianos en una época de angustia: algunos aspectos de la experiencia religiosa desde Marco Aurelio a Constantino, Madrid: Araujo, pp. 33-35). Los cristianos acabaron considerando que cada uno de ellos encarnaba uno de los pecados capitales.
} 
momento, el espíritu arrojó al muchacho al suelo, haciéndole retorcerse y echar espuma por la boca. Al despertar, al cabo de unas horas, contaba haber visto durante el trance a Siméon expulsar de su cuerpo a un perro negro, golpeándolo con un crucifijo de madera (VSym [149-150]).

En el segundo, Simeón expulsa a otro demonio del callejón situado junto a una tienda de posca propiedad de un matrimonio de herejes acéfalos ${ }^{12}$. Tocando una pandereta y rezando una oración apotropaica, el monje expulsa al espíritu que, en su huída, recorre la tienda disfrazado de etíope ( $A_{i} \theta^{\prime}(\circ \psi)$ ), rompiendo todo a su paso. Después, revela a la afligida dueña que él es el responsable de la llegada del "oscuro" (ó raṽoos), y le advierte que los destrozos continuarán a diario a menos que ella y su marido se conviertan a la ortodoxia. Tras otra visita destructiva del negro al día siguiente, según lo anunciado por el monje, el matrimonio se convierte (VSym [153-154]).

Por último, en el tercer episodio, Simeón arrebata un alma de un ciudadano rico al demonio que pretende hacerse con ella $(\operatorname{Vsym}[165-166])^{13}$. Se trataba de un notable de la ciudad, a cuya casa solía ir el monje a hacer bufonadas, que había caído gravemente enfermo. A punto de morir, en sueños, el rico se veía a sí mismo jugando a los dados con un etíope, que era la muerte (Өávatos [165.16] $)^{14}$. Cuando le llegó el turno de tirar los dados, necesitaba obtener un triple 6, de lo contrario moriría. Justo entonces, se le apareció Simeón y le dijo que tiraría los dados por él para ganar al negro si le juraba no volver a mancillar el lecho de su mujer. Como el hombre accedió, el monje lanzó los dados y obtuvo la tirada

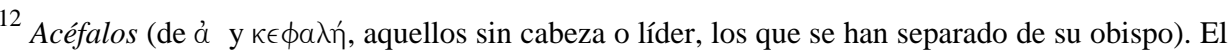
término designaba en origen a los monofisitas estrictos de Egipto que se desligaron de la autoridad del Patriarca de Alejandría Pedro III por haber éste aceptado el compromiso sobre Calcedonia propuesto por el emperador Zenón en su Henotikón del 482 d. C., aunque luego también se empleó (y así lo hace Leoncio en la VSym) para designar como "acéfala" a la herejía de los severianos, monofisitas seguidores de Severo de Antioquía, por ser también éste contrario al dogma difisita aprobado en el Concilio de Calcedonia del 451 d. C. Cf. J. Simón PALMER (1993). El monacato oriental en el Pratum Spirituale de Juan Mosco, Madrid: Fund. Univ. Española, pp. 378-382.

${ }^{13}$ Leoncio lo designa como la Muerte, pero su aspecto de etíope y el hecho de que sólo pueda hacerse con el alma del hombre si éste corrompe su lecho conyugal [166.2-3], nos permite identificarlo como otro demonio.

${ }^{14}$ El motivo de jugar a los dados con la muerte [165.18], está inspirado en la historia de Rhampsinitus (Rameses III) y Démeter, recogida por Heródoto (Historias, II, 122), como ha señalado J. Simón Palmer, que también nos revela que Leoncio, o la tradición sobre Simeón, se inspiraría incluso en el folklore popular del mundo antiguo. Cf. J. SIMÓN PALMER (1995). «La aretalogía cristiana en la Vida de Simeón el Loco, de Leoncio de Neápolis». Erytheia 16, p. 34. 
necesaria. Al despertarse el enfermo, Siméon le recordó su juramento, advirtiéndole antes de marcharse que si faltaba a su palabra, el negro lo ahogaría.

Como puede verse, lo que caracteriza al aspecto demoníaco, humano o animal, en todos los episodios es su apariencia oscura. Esta particularidad cromática tiene el objetivo de caracterizar como maligna a la forma asumida por el demonio. No obstante, mientras que en el caso del perro el color negro es sólo un rasgo cromático, en los dos últimos el matiz llega a concretarse más, hasta definir explícitamente un tipo somático y racial. El demonio no sólo es negro, sino además "etíope". Examinaremos, a continuación de dónde proviene una apariencia tan particular

\section{DEMONIOS NEGROS}

Como ha estudiado L. Cracco Ruggini, la imagen oscura de los demonios no era algo exclusivo del Cristianismo ${ }^{15}$. El negro es el color de la noche, la muerte y las tinieblas, ámbitos oscuros sobre las que se proyectan las ansiedades y temores del hombre ante lo desconocido. Por ello, este color ha sido asociado desde antiguo a las potencias y espíritus malignos. En la Antigua Grecia, éste era el color de las divinidades ctónicas, infernales y funestas, como Hades, Perséfone o Hécate, a las que se sacrificaban víctimas de color negro. En Roma existe también la asociación del color negro a lo maligno, los "démones" funestos, los espíritus infernales y de los muertos, como los Manes (a los que se arrojaban habas negras como alimento). Estos prejuicios clásicos se vieron reforzados en época helenística por la influencia cultural de Oriente, que también asociaba las figuras demoníacas con un aspecto oscuro. Fruto de esta combinación, el tópico del color oscuro de los demonios alcanzó una gran popularidad en adelante y el uso del apelativo $\mu$ é $\lambda a \varsigma$ o niger para caracterizar a los demonios en la literatura fue frecuente. Por ejemplo, Luciano de Samosata, en el s. II d. C., describe en sus obras al menos la aparición de dos demonios negros, uno de ellos invocado por un mago sirio ${ }^{16}$. Tales referencias, a pesar del tono burlesco que caracteriza al autor, revelan la presencia y el arraigo del estereotipo en la mentalidad popular.

15 Cf. L. CRAcCo RugGini (1979). «Il negro buono e il negro malvagio nel mondo classico». En SORDI, M. (a cura di). Conoscenze etniche e rapporti di convivenza nell'antichità, Contributi dell'Instituto di storia antica, VI, Milano: Pubblicazioni della Università Cattolica del Sacro Cuore, pp. 108-135; para un estudio general de los individuos de raza negra en la Antigüedad v. F. M. SNOWDEN (1970). Blacks in Antiquity, Ethiopians in the Greco-Roman Experience, Cambridge: Harvard University Press, y G. BYRON (2002). Symbolic Blackness and Ethnic Difference in Early Christian Literature, London: Routledge, en el ámbito del Cristianismo.

\footnotetext{
${ }^{16}$ Luc. Sam., Philoseudes, 16 y 31.
} 
El Cristianismo, debido a la herencia del judaísmo intertestamentario, fuertemente influido por el Zoroastrismo iranio, compartía estos mismos prejuicios hacia la oscuridad. Toda la literatura evangélica está plagada de ellos en la forma de referencias a la lucha entre el bien y el mal, el Reino de Dios y el Reino de Satán, expresada metafóricamente en términos de Luz y Tinieblas ${ }^{17}$. Frente a los justos, "hijos de la luz", se alzaban los demonios y los hombres malvados, alineados con Satán, los "hijos de las Tinieblas". El Cristianismo posterior mantuvo esta idea, utilizando el color negro como sinónimo del pecado y los demonios, como puede verse muy profusamente en los textos del s. II d. C., donde

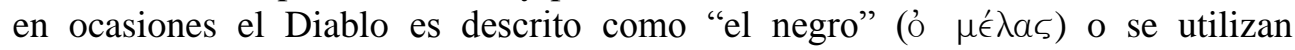
referencias a elementos negros u oscuros para simbolizar los vicios y los pecadores que a ellos sucumben ${ }^{18}$.

En suma, fruto de diversos prejuicios, la caracterización de los demonios como figuras oscuras y el uso del apelativo Mé $\lambda a \varsigma$ o niger para describirlos fue frecuente en la literatura, tanto pagana como cristiana ${ }^{19}$. Pero los demonios que veían Simeón el Loco y sus conciudadanos no sólo eran negros, sino además "etíopes", lo que implica un componente racial que requiere una explicación más precisa.

\section{LA IMAGEN DEL ETÍOPE Y SU ASOCIACIÓN CON LOS DEMONIOS.}

La vinculación entre los demonios y los hombres de raza negra provenía en origen de esos mismos prejuicios que acabamos de describir, los cuales vinculaban

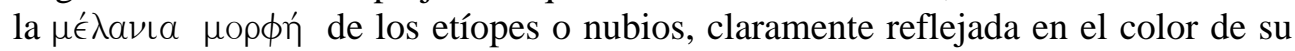
piel, con una valoración negativa de estos individuos. Debido a esta asociación, la imagen de los etíopes en el Mundo Antiguo era ambigua. Si durante el periodo griego hubo opiniones diversas, tanto positivas como negativas, ${ }^{20}$ conforme avanza el tiempo y la cronología romana, la imagen etiópica va cargándose de prejuicios negativos y su asociación con los demonios se intensifica. De hecho, encontramos referencias textuales que los vinculan directamente con ellos y con los omina de muerte. Recuérdese que el encuentro del ejército de Bruto y Casio con un soldado

${ }^{17}$ Cf. Mt 5: 14-16; Jn 12: 35-36; II Cor 6: 14; Col 1: 13; Ef 2: 2, 5: 9-11; I Jn 1: 6-7, 2: 8-11; Ap 4: 5, 7: 16; 8: 5-12, 9, 12, 16: 17, 20-21.

${ }^{18}$ Para el Diablo cf. Ep. Bernab., 3: 9; en Hermas (Pastor, Par. IX, 13-14), unas jóvenes de ropa oscura y unas piedras negras simbolizan los vicios y los pecadores que han caído en ellos.

19 Cf. L. CRACCO RUGGini (1979), op. cit, p. 14.

20 v. L. CRACCO RUGGINI (1979), op. cit, p. 111, que cita numerosas referencias textuales, desde Homero a Eliano, con bibliografía, y también A. BALLABRIGA (1986). Le soleil et le Tartare- L'image mythique du monde en Gréce archaique, Paris: Éditions de l'École des hautes études en sciences sociales, pp. 190-215. 
etíope, fue tomado por un presagio funesto, según Floro (Ep. II, 17: 8), o que en tiempos de Calígula los etíopes eran utilizados en el teatro para representar a los habitantes de los infiernos (Suetonio, Vit. Caes., Calígula, 57).

En el Cristianismo también se dio esta ambigüedad. La postura oficial era defender que todos los hombres eran iguales ante Dios, sin diferencias de raza o color de piel. Como señalaba Orígenes, en el siglo III d. C., la gracia "blanquearía a

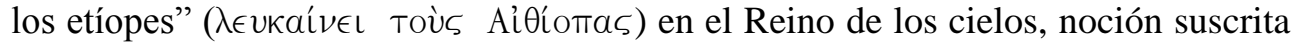
posteriormente por Atanasio de Alejandría, Basilio de Cesarea y Gregorio de Nacianzo, entre otros ${ }^{21}$. Esta postura, si bien garantizaba por un lado a los etíopes la posibilidad de redención, por otro, implicaba también el reconocimiento implícito de la imagen del etíope como símbolo del pecado y justificaba en cierta medida el que los cristianos percibieran a los demonios bajo esta apariencia. De esta forma, los textos apócrifos de mediados del s. III d. C., documentos muy pródigos en cuestiones demonológicas, contienen referencias verdaderamente espectaculares que nos hablan, por ejemplo, de la poderosa arconte Ariûth, la

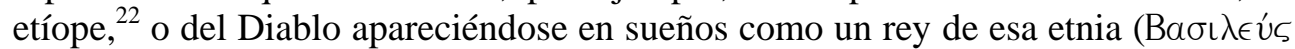
å̇óo $\psi)^{23}$.

Esta tendencia a la demonización del etíope se dio sobre todo en los textos monásticos de la Antigüedad Tardía, particularmente en aquellos provenientes de Egipto. En este contexto, los monjes egipcios, cuya etnia también acarreaba los prejuicios negativos relativos a la piel oscura (e. $g$. la mártir Perpetua veía al Diablo bajo la forma de un gigantesco gladiador egipcio) ${ }^{24}$, los proyectaban a su vez sobre aquellos más oscuros que ellos: los etíopes. Este proceso también se vio sin duda incentivado por las incursiones violentas en la región a partir del s. III d. C. de las tribus bárbaras de etíopes nubios (Blemmyes, Nobades o Aksumitas), muchas dirigidas contra monasterios $\operatorname{coptos}^{25}$. Además, en este ámbito egipcio, la epifanía demoníaca con forma de etíope se redefinió, apreciando algunos investigadores como D. Brakke cierta propensión a utilizarla para representar una tentación de carácter específicamente erótico y al demonio de la fornicación. La

${ }^{21}$ Oríg. De prin. II, 9, 5; Atan. Orat. De. Incar. Verb. 51; Bas. Cas. Ep. 130, Greg. Naz. Or. IV In Iulianum. Cf. L. CRACCo RUGGini (1979), op. cit, pp. 122-123.

${ }^{22}$ Cf. Pistis Sophia, 140 (libro V).

${ }^{23}$ Acta Xanthippae et Polixenae, 17-18; tomo la cita de L. CRACCO RUGGini (1979), op. cit, p. 126, que sigue la edición de M. R. James, de 1893, al no haberme sido posible acceder al texto original.

${ }^{24}$ Cf. Passio Perpetua et Felicitas, 10.

25 Como ya señaló en su día N. Fernández MArcos (1974). «Demonología de los Apophthegmata Patrum». Cuadernos de Filología Clásica 4, p. 477. 
primera referencia aparece en la Vita Antonii de Atanasio de Alejandría, con el spiritus fornicationis presentándose ante Antonio, una vez derrotado, bajo la apariencia de un niño negro (niger puer) ${ }^{26}$. En este texto el demonio todavía es sólo negro, pero poco después lo encontramos de nuevo, descrito ya específicamente como una joven "etíope" (Aïıomis) tratando de seducir por la noche al monje Pacón, según cuenta Paladio, o atormentando a los monjes en varios apophthegmata ${ }^{27}$.

Tras este uso específico de los etíopes para encarnar un pecado de carácter sexual, yacían prejuicios fisionómicos greco-romanos. Como ha señalado Brakke, la cultura clásica greco-romana concebía a un etíope no en términos raciales, sino corporales, como un estereotipo somático concreto al que se adscribían una serie de rasgos: piel negra, nariz gorda, labios anchos, pelo rizado..., y sobre todo hipersexualidad $^{28}$ (independientemente de las peculiaridades físicas o la libido particular que tuviera cada etíope concreto). De ahí que se considerara a los etíopes más proclives al sexo que el resto de personas y que los monjes egipcios acabarán concibiendo al demonio de la fornicación con ese aspecto, por asociación semántica.

Una vez acuñado el estereotipo de la apariencia etíopica de los demonios, tuvo un gran éxito y la influencia de la literatura monástica egipcia lo difundió al resto de regiones cristianas, convertido ya en un topos literario ${ }^{29}$. La imagen se popularizó en los textos hagiográficos, más allá de esa vinculación con los pecados sexuales, apareciendo también en las fuentes demonios etíopes relacionados, por ejemplo, con la soberbia y el orgullo ${ }^{30}$.

Es dentro de esta condición de mero cliché literario, vehiculado a lo largo de las distintas épocas y regiones por los textos hagiográficos, como se explica el aspecto de etíope con el que se representa a los demonios en la VSym. En el texto de Leoncio el motivo es sólo ornamental, para dar efecto dramático a la narración. No queda traza alguna en el texto que asocie esta apariencia demoníaca con un pecado de índole sexual o con el demonio de la fornicación. Tal vez en el caso del

${ }^{26}$ Cf. Atan. Alejan. Vita Antonii, 5-6.

${ }^{27}$ Cf. Paladio, Hist. Laus. 23: 5-6; Apophthegmata Patrum. Collec. Syst. V, 27; utilizo la edición de GUY (1993-2005).

${ }^{28}$ Cf. D. BraKke (2001). «Male Sexuality, the Black-Skinned Other, and the Monastic Self». Journal of the History of Sexuality 10, No 3-4 (Jul.- Oct.), passim, que se basa, entre otros autores, en la redacción previa de la obra de G. BYRON (2002), op. cit.

${ }^{29}$ Cf. L. Cracco RugGini (1979), op. cit, pp. 131-132.

${ }^{30}$ Cf. Historia Monachorum, 8: 4; Juan Casiano, Collat. I, 21: 1; Teodoreto de Ciro, Hist. Rel. 21. 
ciudadano rico podría aceptarse la identificación, puesto que el adulterio puede asimilarse a la fornicación y la apariencia del demonio — o de la Muerte como ente negativo demonizado, más bien-sí es la de un etíope, pero esto no ocurre en los otros dos ejemplos. Por un lado, en el caso del hijo del diácono Juan, aunque el muchacho está explícitamente poseído por fornicar, la forma que adopta el demonio cuando Simeón lo expulsa es la de un perro negro, no un etíope; por otro, el demonio que Simeón envía contra los vendedores de posca, sí tiene apariencia etíope, a pesar de que el pecado del matrimonio es pertenecer a la herejía acéfala, falta que, a priori, carece de semántica erótica ${ }^{31}$.

Si se acude a otros textos hagiográficos bizantinos de cronología similar a la VSym para buscar un punto de comparación, se obtienen conclusiones similares. La mejor opción parece el Prado Espiritual ( $\left.\epsilon \iota \mu \omega \omega^{\prime}\right)$, de Juan Mosco, texto de comienzos del siglo VII d. C. que influyó notablemente en la biografía escrita por Leoncio $^{32}$. El demonio de la fornicación también está muy presente en el Pratum $(P r)^{33}$, aunque lamentablemente Mosco no describe nunca su aspecto. Este silencio sobre la apariencia de los demonios se extiende en general al resto de la obra ${ }^{34}$. Sólo hay tres excepciones, todas de demonios "anónimos": el capítulo 161, donde

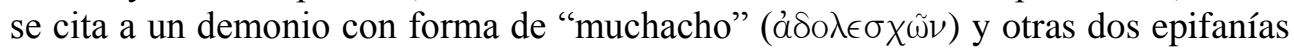
con aspecto de etíope. En la primera ( $\operatorname{Pr} 30)$, un demonio con esta apariencia atormenta a un hereje acéfalo que ha obligado a su mujer a vomitar la comunión ortodoxa. En la segunda $(\operatorname{Pr} 66)$, más espectacular, un anacoreta ve en una visión a

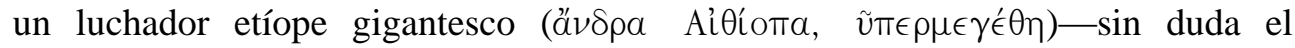
Diablo, en una imagen similar al caso de la mártir Perpetua, sólo que ella lo veía como un egipcio - al que tendrá que enfrentarse en la arena de un anfiteatro cuyas gradas abarrotan, a partes iguales, ángeles y demonios descritos como espectadores

${ }^{31}$ La herejía y la idolatría son consideradas en la Biblia metafóricamente como una "fornicación del alma" (Os 1,2; Gal 5: 19-21), idea también presente en la hagiografía bizantina (cf. Juan Mosco, Pratum 188 [vid. infra]), pero utilizar esta asociación para identificar al etíope que destroza la tienda de posca con el demonio de la fornicación parece, en mi opinión, forzar demasiado el significado del texto.

32 Para el texto del Prado Espiritual (Patrum Spirituale) de Mosco sigo la traducción de J. SiMÓN PALMER (1999). Historias Bizantinas de locura y santidad..., pp. 45-231 y la edición clásica de J.P. MiGNE $P G$ 87c col. 2852-3116 para el texto griego.

${ }^{33}$ Cf. $\operatorname{Pr} 14,19,45,97,104$. Merece destacarse el capítulo 97, en el que este demonio ataca a dos hermanos espirituales que han jurado no separarse, en un marcado paralelismo con Simeón y Juan en el texto de Leoncio (en inicio, éste último sólo habla de tentaciones de añoranza de familiares, hastío por la vida ascética y deseo de carne y vino (cf. VSym [138-141]), pero luego Simeón revela al diácono Juan que el demonio de la fornicación también lo asaltaba en el desierto, cf. VSym [155]).

${ }^{34}$ Cf. $\operatorname{Pr} 49,63,68,177,182$. 
vestidos de blanco y etíopes vestidos de negro, respectivamente. Como puede verse, en la obra de Mosco ya aparecen los rasgos que luego encontraremos en la VSym: se utiliza la imagen etíope para describir ocasionalmente a unos demonios cuya apariencia en general no se especifica, pero sin vincularla en absoluto con el sexo o la fornicación.

Finalmente, una breve selección de referencias de tratadistas bizantinos sobre demonología permitirá corroborar, también desde la perspectiva teórica, cómo la "etiopicidad" de los demonios bizantinos, y en especial del demonio de la fornicación, perdió su significado sexual conforme avanza la cronología bizantina. Ya Evagrio Póntico, todavía en el Egipto del s. IV d. C., evocaba únicamente la imagen de la mujer, principal fuente de lujuria, cuando advertía en su Antirrhêtikos frente a las insidias del demonio de la fornicación ${ }^{35}$. Por su parte, un autor contemporáneo de Leoncio de Neápolis, Juan Clímaco (s. VII d. C.), presentaba en su Escala del Paraíso a este malvado espíritu como hijo de la Gula y muy combativo, capaz de nublar la razón y reducir al hombre a la condición bestial, pero utilizaba sólo imágenes de animales (principalmente la serpiente) para ilustrar sus palabras. Incluso en la referencia más apurada, sólo llega a describirlo como un "egipcio" (AijúmTlo5), no un etíope ${ }^{36}$. La tendencia parece proseguir en épocas posteriores, puesto que en el De operatione daemonum de Miguel Pselos, de cronología muy posterior (s. XI d. C.) aunque con descripciones mucho más precisas, tampoco aparece el etíope entre los muchos ejemplos de apariencia demoníaca que cita este autor (león, pantera, jabalí, perros, cuervos, hombre, mujer.... $)^{37}$. Como puede verse, este rápido repaso de algunos de los principales tratadistas bizantinos sobre demonología reafirma lo ya dicho acerca de que el aspecto etiópico de los demonios en la VSym responde únicamente a la perpetuación de motivo hagiográfico, sin conexión con un pecado sexual.

${ }^{35}$ Cf. Evagrio Póntico, Antirrhêtikos, II, 1.15.32.35.37.49.56. Me sirvo de la traducción. inglesa de D. BRAKKe (2009). Evagrius of Pontus: Talking Back. A Monastic Handbook for Combating Demons, Collegeville (Minnesota): Cistercian Publications.

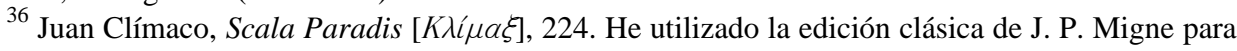
el texto griego $P G$ 88, col. 632-1164 (la ref. al "egipcio" aparece en col. 887D).

37 Merece destacarse, no obstante, que Pselos considera que los demonios pueden adquirir cualquier forma, y que uno de los seis tipos de demonios descritos por este autor, el "lucífugo", es irracional como una bestia y suele atormentar a sus víctimas con un trance epiléptico (De op. daem. 27 y 39 [he utilizado la traducción castellana de J. Curbera Costello (1991). Miguel Pselo. Opúsculos, Madrid: Ediciones Clásicas]), descripción que encaja con la posesión del hijo del diácono Juan en VSym [149-150] por un demonio con aspecto de perro negro. 
No sólo negros, sino "etíopes”: la apariencia oscura de los demonios en la Vida de Simeón el Loco, ...

\section{CONCLUSIÓN}

Como he tratado de mostrar, la apariencia de etíope que adoptan algunos demonios en la VSym es el resultado de la confluencia de ideas procedentes de varias tradiciones culturales (Mazdeísmo, cultura greco-romana, Cristianismo) y presenta dos componentes principales, uno cromático (el color negro), y otro étnico (la raza etíope). Si bien el primero procedería de la asociación de las tinieblas con las fuerzas malignas en la tradición cristiana, el segundo parece haberse incorporado en la Antigüedad Tardía, al sumarse a esta idea una combinación de estereotipos raciales y sexuales romanos con la hostilidad del monacato egipcio hacia los bárbaros etíopes.

Una vez establecida, la forma etíope del demonio aparecerá a menudo en la literatura hagiográfica posterior, aunque con el paso del tiempo perdió cierto componente sexual que tuvo en inicio, como se observa ya a comienzos de la época bizantina. La explicación de esta evolución yace en la propia variación del contexto socio-ideológico. Los monjes egipcios de la Antigüedad Tardía habitaban un mundo en el que la tradición clásica todavía constituía la base del pensamiento, llegando sus prejuicios somáticos a condicionar la percepción cristiana y haciendo en algún momento "etíopes" a unos demonios antes sólo negros, por el significado sexual adscrito a estos individuos en aquella tradición. Por el contrario, los habitantes de la Emesa del s. VI vivían en una sociedad ya bizantina y plenamente cristiana, en la que tal asociación carecía de marco ideológico que la respaldase. En esta época, el motivo del demonio etíope constituía ya sólo un elemento del folklore demonológico, carente de un significado más específico. Una misma tradición religiosa y hagiográfica unía ambas sociedades, lo que explica la continuidad de la imagen etiópica del demonio, pero ésta era percibida desde dos mentalidades distintas, estrechamente vinculadas, pero diferentes en última instancia.

\section{BIBLIOGRAFÍA}

ACERBI, S.; TEJA, R. (2011). «En las raíces del eremitismo cristiano: La vida en el desierto concebida como conquista del cielo en la tierra». En GARCÍA DE CORTÁZAR, J. A. y TEJA, R. (coords). El monacato espontáneo. Eremitas y eremitorios en el mundo medieval, Aguilar de Campoo: Fundación $\mathrm{St}^{\mathrm{a}} \mathrm{M}^{\mathrm{a}}$ la Real, pp. 9-30.

Ballabriga, A. (1986). Le soleil et le Tartare- L'image mythique du monde en Gréce archaique, Paris: Éditions de l'École des hautes études en sciences sociales. (non vidit).

BRAKKE, D. (2001). «Male Sexuality, the Black-Skinned Other, and the Monastic Self». Journal of the History of Sexuality 10, No 3-4 (Jul.- Oct.), pp. 501-535.

BrakKe, D. (2009). Evagrius of Pontus: Talking Back. A Monastic Handbook for Combating Demons, Collegeville (Minnesota): Cistercian Publications, 
Byron, G. (2002). Symbolic Blackness and Ethnic Difference in Early Christian Literature, London: Routledge,

CRACCO RUGGINI, L. (1979). «Il negro buono e il negro malvagio nel mondo classico». En SORDI, M. (a cura di). Conoscenze etniche e rapporti di convivenza nell'antichità, Contributi dell'Instituto di storia antica, VI, Milano: Pubblicazioni della Università Cattolica del Sacro Cuore, pp. 108-135.

Curbera Costello, J. (1991). Miguel Pselo. Opúsculos, Madrid: Ediciones Clásicas,

DAgron, G. (1990). «L'homme sans honneur ou le saint scandaleux». Annales ESC, 4 (juillet-août), pp. 929-939.

DEROCHE, V. (1995). Études sur Léontios de Néapolis, Uppsala: Uppsala Universitet,

DodDs, E. R. (1975). Paganos y cristianos en una época de angustia: algunos aspectos de la experiencia religiosa desde Marco Aurelio a Constantino, Madrid: Araujo,

FERNÁNDEZ MARCOS, N. (1974). «Demonología de los Apophthegmata Patrum». Cuadernos de Filología Clásica 4, pp. 463-491.

Festugière, A. J. (1974). Léontius de Neápolis, Vie de Simeón Le Fou et Vie de Jean de Chypre, Paris.

GROSDIDIER DE MATONS, J. (1970). «Les thèmes d'edifications dans la Vie d'André Salos». Travaux et Mémoires 4, pp. 277-328.

GuY, J. C. (1993-2005). Les Apophtegmes des pères. Collection systèmatique, (SC 387, 474,498), Paris: Les Éditions du Cerf,

IvAnOv, S. A. (2006). Holy Fools in Byzantium and Beyond, New York: Oxford University Press,

Krueger, D. (1996). Simeón the Holy Fool. Leontius's Life and the Late Antique City, Berkeley/ Los Angeles/ London: University of California Press.

Monaci Castagno, A. (1996). Il Diavolo e i suoi Angeli. Testi e tradizioni (secoli I-III), Fiesole: Nardini editore.

PricoCo, S. (1995). Il Demonio e i suoi Complici. Dottine e credenze demonologiche nella Tarda Antichità, Messina: Rubettino.

RYDÉN, L. (1981). «The Holy Fool». En HACKEL, S. (ed.). The Byzantine Saint. University of Birmingham Fourteenth Spring Symposium of Byzantine Studies, London, pp. 106113.

Simón Palmer, J. (1993). El monacato oriental en el Pratum Spirituale de Juan Mosco, Madrid: Fund. Univ. Española

Simón PALmer, J. (1995). «La aretalogía cristiana en la Vida de Simeón el Loco, de Leoncio de Neápolis». Erytheia 16, pp. 29-38.

Simón PALMER, J. (1999). «Los santos locos en la literatura bizantina». Erytheia 20, pp. 57-74.

Simón PALMER, J. (1999)². Historias Bizantinas de locura y santidad. Juan Mosco, El Prado. Leoncio de Neápolis, Vida de Simeón el loco, Introducción traducción y notas de José Simón Palmer, Madrid: Siruela.

SNowden, F. M. (1970). Blacks in Antiquity, Ethiopians in the Greco-Roman Experience, Cambridge: Harvard University Press.

Sorensen, E. (2002). Possession and Exorcism in the New Testament and Early Christianity, Tübingen: Mohr Siebeck. 
No sólo negros, sino "etíopes”: la apariencia oscura de los demonios en la Vida de Simeón el Loco, ...

SYRKIN, A. Y. (1982): «On the Behaviour of the "Fool for Christ' Sake». History of Religions, 22 (Nov. 1982), pp. 150-171.

VILler, F; CAVAllera, F; DE GuIBert, J. (1957). Diccionnaire de Spiritualité ascétique et mystique, III, Paris: Beauchesne, voz : démon (pp. 142-189). 